\title{
Microstructural Evolution and Softening Behavior of Simulated Heat-Affected Zone in 2219 Aluminum Alloy
}

\author{
Xin-Jie Di ${ }^{1} \cdot$ Hui-Juan Xie ${ }^{1}$ C Cui-Xin Chen ${ }^{2} \cdot$ Cai-Yan Deng ${ }^{1} \cdot$ Dong-Po Wang $^{1}$
}

Received: 8 November 2016/Revised: 17 March 2017/Published online: 5 May 2017

(C) The Chinese Society for Metals and Springer-Verlag Berlin Heidelberg 2017

\begin{abstract}
The effect of peak temperature $\left(T_{\mathrm{p}}\right)$ at $200,300,400,500$ and $550{ }^{\circ} \mathrm{C}$ on the microstructural evolution and softening behavior of the simulated heat-affected zone (HAZ) was studied in the 2219-T87 alloy by electron-backscatter diffraction, transmission electron microscopy, X-ray diffraction, micro-hardness and micro-tensile tests. The results showed that the grain size in the HAZs at $200-500{ }^{\circ} \mathrm{C}$ was comparable, but the number density of the strengthening precipitates (GP zones $/ \theta^{\prime}$ ) decreased with increasing $T_{\mathrm{p}}$. At a $T_{\mathrm{p}}$ of $550{ }^{\circ} \mathrm{C}$, the grain size significantly decreased and the distribution of the misorientation angles corresponded to the MacKenzie distribution. The GP zones $/ \theta^{\prime}$ phase coarsened and translated into $\theta$ phases at $T_{\mathrm{p}}$ values in the range of $200-400{ }^{\circ} \mathrm{C}$. Increasing the $T_{\mathrm{p}}$ to $500{ }^{\circ} \mathrm{C}$ and above, some $\theta^{\prime}$ phases translated into $\theta$ phases and others dissolved into the $\alpha$-Al matrix which led to an increase in the solid solution strengthening. The reduction of the number density of the GP zones/ $\theta^{\prime}$ was responsible for the softening behavior.
\end{abstract}

KEY WORDS: 2219 aluminum alloy; Peak temperature of thermal cycles; Electron-backscatter diffraction (EBSD); Softening behavior; Precipitates

\section{Introduction}

The 2219-T87 aluminum alloy is an $\mathrm{Al}-\mathrm{Cu}-\mathrm{Mn}$ alloy with excellent mechanical properties over a wide temperature range from -250 to $250^{\circ} \mathrm{C}[1,2]$. Accordingly, this is the preferred candidate material for the fuel tanks of large launch vehicles. For these large and complex shaped fuel tanks, reliable and durable welding joints made from the 2219 aluminum alloy are critical. Components made from the 2219 aluminum alloy have an advantage over the $\mathrm{Al}-\mathrm{Si}-\mathrm{Mg}$

Available online at http://link.springer.com/journal/40195

Cai-Yan Deng

dengcaiyan@tju.edu.cn

1 School of Materials Science and Engineering, Tianjin University, Tianjin 300350, China

2 School of Materials Science and Engineering, Hebei University of Technology, Tianjin 300130, China and $\mathrm{Al}-\mathrm{Zn}-\mathrm{Mg}$ alloys in terms of weldability [3, 4], but the efficiency of the welded joints only reaches values from $60 \%$ to $70 \%$ [2, 4-6]. Many studies have indicated that the strength of these heat-treatable alloys is mainly influenced by the dissolution or growth of the strengthening precipitates [7, 8]. The precipitation sequence of the 2219 aluminum alloy usually includes the following five sequential structures: supersaturated solid solution $\rightarrow$ GP zone $\rightarrow$ metastable $\theta^{\prime \prime}$ phase $\rightarrow$ metastable $\theta^{\prime}$ phase $\rightarrow$ stable $\theta$ $\left(\mathrm{Al}_{2} \mathrm{Cu}\right)[9,10]$. The major strengthening phases are the distributed nano-scaled disk-shaped GP zones and the $\theta^{\prime}$ aging phases, although other phases, such as the $\mathrm{T}$ phases and the $\mathrm{Al}-\mathrm{Cu}-\mathrm{Fe}-\mathrm{Mn}$ phases, have also been reported in the literature [11,12]. Recently, numerous studies have focused on the influence of the post-weld heat treatment (PWHT) on the microstructure and mechanical properties of the 2219 alloy joints [13, 14]. Malarvizhi et al. [13] considered that the weld metal region of the PWHT joints consists of a very fine and uniform distribution of precipitates, resulting in superior tensile and hardness properties. Luo et al. [14] also reported 
that the tensile strength of the joints can reach $90 \%$ of the base metal by the PWHT. Ma et al. [15] investigated the softening behavior of $\mathrm{Al}-\mathrm{Zn}-\mathrm{Mg}$ alloys in welding and found a great softening tendency in both the dissolution zone and the overaging zone. Wool et al. [7] reported that softening occurs in a wide region of the friction stir welding 6061-T6 aluminum alloy due to the dissolution of the strengthening precipitates.

However, there have not been detailed studies of the influence of the thermal cycle on the softening behavior of the HAZ during cooling of the 2219-T87 aluminum alloy after welding. The objective of this investigation was to study the influence of the thermal cycle peak temperature $\left(T_{\mathrm{p}}\right)$ on the microstructural evolution and the softening behavior of the simulated HAZ in the 2219-T87 aluminum alloy.

\section{Experimental Procedures}

The base material (BM) was the 2219-T87 aluminum alloy in the form of an 8-mm-thick plate with a chemical composition (wt $\%$ ) of $6.33 \mathrm{Cu}, 0.34 \mathrm{Mn}, 0.13 \mathrm{Fe}, 0.12 \mathrm{Zr}, 0.07 \mathrm{~V}$, $0.04 \mathrm{Ti}, 0.06 \mathrm{Si}, 0.02 \mathrm{Zn}$, balance Al. The mechanical properties are listed in Table 1. The dimension of the samples used for the thermal simulation was $\varphi 6.0 \times 70 \mathrm{~mm}$. The regions in the HAZ undergoing different thermal cycles in the realistic welding joints are difficult to be separated accurately. Therefore, the simulation of the HAZ with different $T_{\mathrm{p}}$ was carried out by using a Gleeble-3500 thermal simulator. The welding temperature field can be described as [16]

$T=\frac{E / \delta}{2(\pi \lambda \rho c t)^{1 / 2}} \mathrm{e}^{\frac{-y_{0}^{2}}{4 a t}}$,

where $E$ is the welding heat input $(\mathrm{J} / \mathrm{cm}), \delta$ is the thickness of the plate, $\rho$ is the density of the material, $y_{0}$ is the distance to the center of weld, $\lambda$ and $c$ are the thermal conductivity and the specific heat capacity, respectively, and $a=\lambda / c \rho$ is the thermal diffusion rate. When $\frac{\partial T}{\partial t}=0, T_{\mathrm{p}}$ can be expressed as $T_{\mathrm{p}}=\frac{0.242 E / \delta}{\rho c y_{0}}$, where $T_{\mathrm{p}}$ is the peak temperature of the thermal cycle. In the present work, the HAZs were simulated with $T_{\mathrm{p}}$ values of $200,300,400,500$ and $550{ }^{\circ} \mathrm{C}$ for a heat input of $7.0 \mathrm{~kJ} / \mathrm{cm}$ (Fig. 1).

Samples for metallographic examination were cut from the middle because only the intermediate $1-2 \mathrm{~mm}$ can

Table 1 Mechanical properties of the 2219-T87 aluminum alloy

\begin{tabular}{llll}
\hline $\begin{array}{l}\text { Yield strength } \\
(\mathrm{Re} / \mathrm{MPa})\end{array}$ & $\begin{array}{l}\text { Ultimate tensile } \\
\text { strength }(\mathrm{Rm} / \mathrm{MPa})\end{array}$ & $\begin{array}{l}\text { Elongation } \\
(\delta / \%)\end{array}$ & $\begin{array}{l}\text { Hardness } \\
\left(\mathrm{HV}_{0.98 \mathrm{~N}}\right)\end{array}$ \\
\hline 395 & 475 & 10 & 135 \\
\hline
\end{tabular}

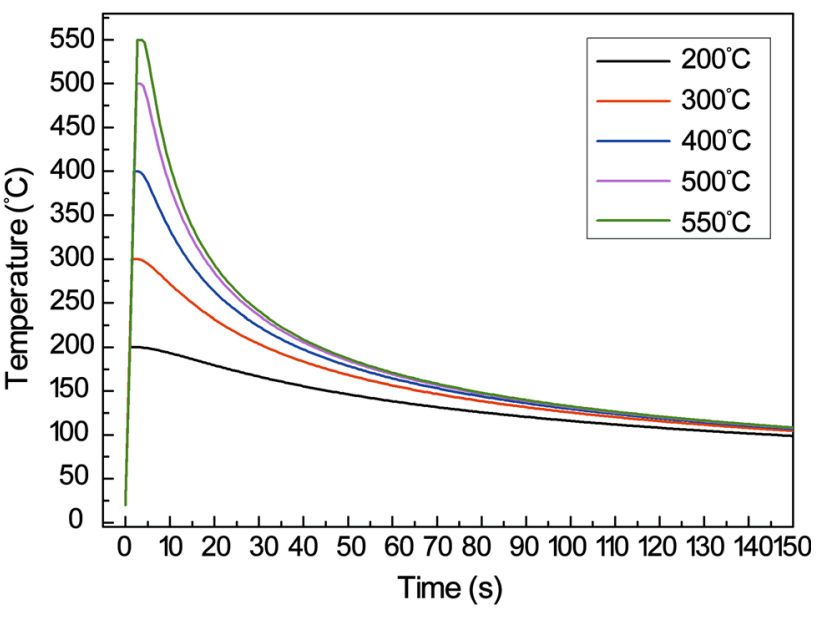

Fig. 1 Thermal cycles simulated the fusion welding process

achieve the desired $T_{\mathrm{p}}$. The samples for microstructure observation were prepared using standard mounting, grinding, and polishing methods, and then etched by Keller's reagent. The samples without chemical etching were electrolytically polished for electron-backscatter diffraction (EBSD) inspection. The EBSD measurement results were obtained by using the commercially available software TSL. The transmission electron microscopy (TEM) thin foils were prepared from 3.0-mm disks that were punched from the simulated samples. The final thinning was performed by the ion-thinning technique. The X-ray diffraction (XRD) was used to measure the lattice parameter of the matrix in the HAZ of the simulated samples. To minimize the calculation error, the diffraction angles between $30^{\circ}$ and $90^{\circ}$ were selected to calculate the lattice parameter using a JADE software to adjust the exact peak angular position of the $\alpha$ phase. The micro-hardness testing was conducted using a 432SVD micro-hardness tester with a 100-g load and 10-s duration. An Instron-5500 electronic universal testing machine was used for the micro-tensile test at a constant loading rate of $1.0 \mathrm{~mm} / \mathrm{min}$. The dimension of the micro-tensile specimens is shown in Fig. 2. Twenty hardness measurement points and three tensile specimens were tested for each condition.

\section{Results and Discussion}

\subsection{Grain Structure and Crystallographic Texture}

The EBSD orientation images of the simulated HAZs are shown in Fig. 3. The grain structure of HAZs for $T_{\mathrm{p}}$ of $200-500{ }^{\circ} \mathrm{C}$ exhibits large grains elongated along the rolling direction. However, at the $T_{\mathrm{p}}$ of $550{ }^{\circ} \mathrm{C}$, the $\mathrm{HAZ}$ is characterized by a relatively fine equiaxed-grain structure. The misorientation angle distributions at different $T_{\mathrm{p}}$ are 


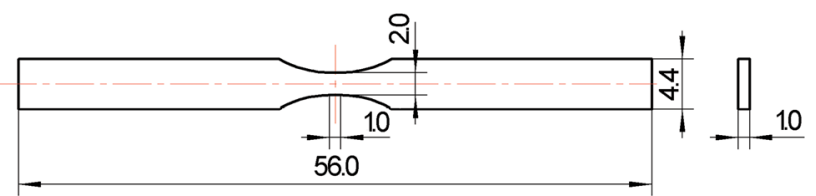

Fig. 2 Dimensions of the micro-tensile specimens (in $\mathrm{mm}$ )

presented in Fig. 4. For $T_{\mathrm{p}}$ in the range of $200-500{ }^{\circ} \mathrm{C}$, the grains contain a large number of sub-boundaries. The relative proportion of low misorientation angles of $2^{\circ}-5^{\circ}$ gradually decreases with increasing $T_{\mathrm{p}}$. This may be ascribed to the recovery and recrystallization process. The high-angle grain boundaries $\left(>15^{\circ}\right)$ are the most prevalent in the simulated HAZ with the $T_{\mathrm{p}}$ of $550{ }^{\circ} \mathrm{C}$. The distribution of misorientation angles in this case corresponded to the MacKenzie distribution [17] (that characterizes a theoretical misorientation angle distribution for a randomly cubic polycrystal), which indicated that significant recrystallization occurred [18]. Figure 5 shows the distribution of the grain diameters at the $T_{\mathrm{p}}$ of 200,400 and $550{ }^{\circ} \mathrm{C}$. The distributions are rather symmetrical relative to the $70-\mu \mathrm{m}$ grains at the $T_{\mathrm{p}}$ of 200 and $400{ }^{\circ} \mathrm{C}$. Additionally, the grains larger than $100 \mu \mathrm{m}$ occupy about $30 \%$ and the mean grain

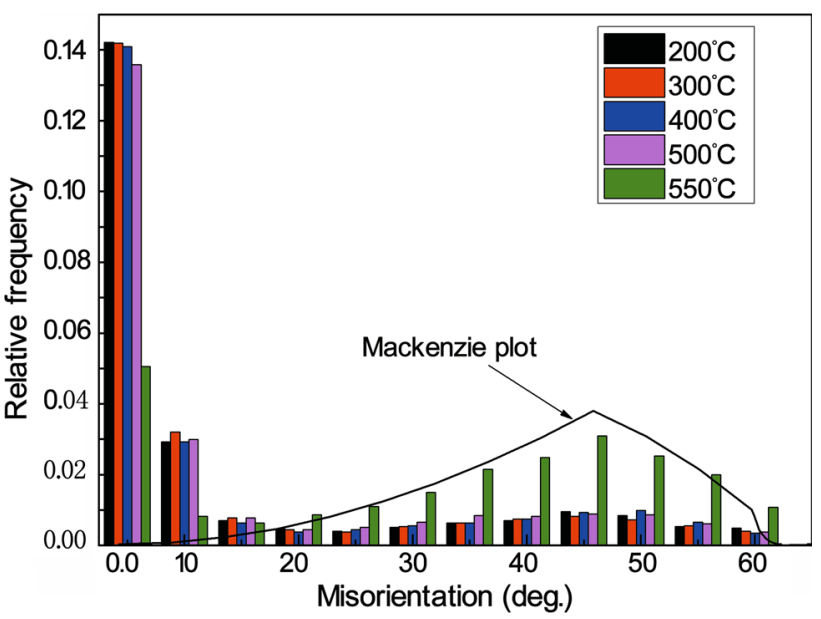

Fig. 4 EBSD determined histograms of the boundary misorientation distribution in the HAZ samples with different $T_{\mathrm{p}}$

diameters are 82 and $78 \mu \mathrm{m}$, respectively, at $T_{\mathrm{p}}$ of 200 and $400{ }^{\circ} \mathrm{C}$, respectively. Conversely, the grain diameter is mainly distributed between 30 and $80 \mu \mathrm{m}$ at the $T_{\mathrm{p}}$ of $550{ }^{\circ} \mathrm{C}$. Therefore, the welding thermal cycle with $550{ }^{\circ} \mathrm{C}$ $T_{\mathrm{p}}$ has a significant influence on the grain size and leads to finer grains with a $50 \mu \mathrm{m}$ diameter.
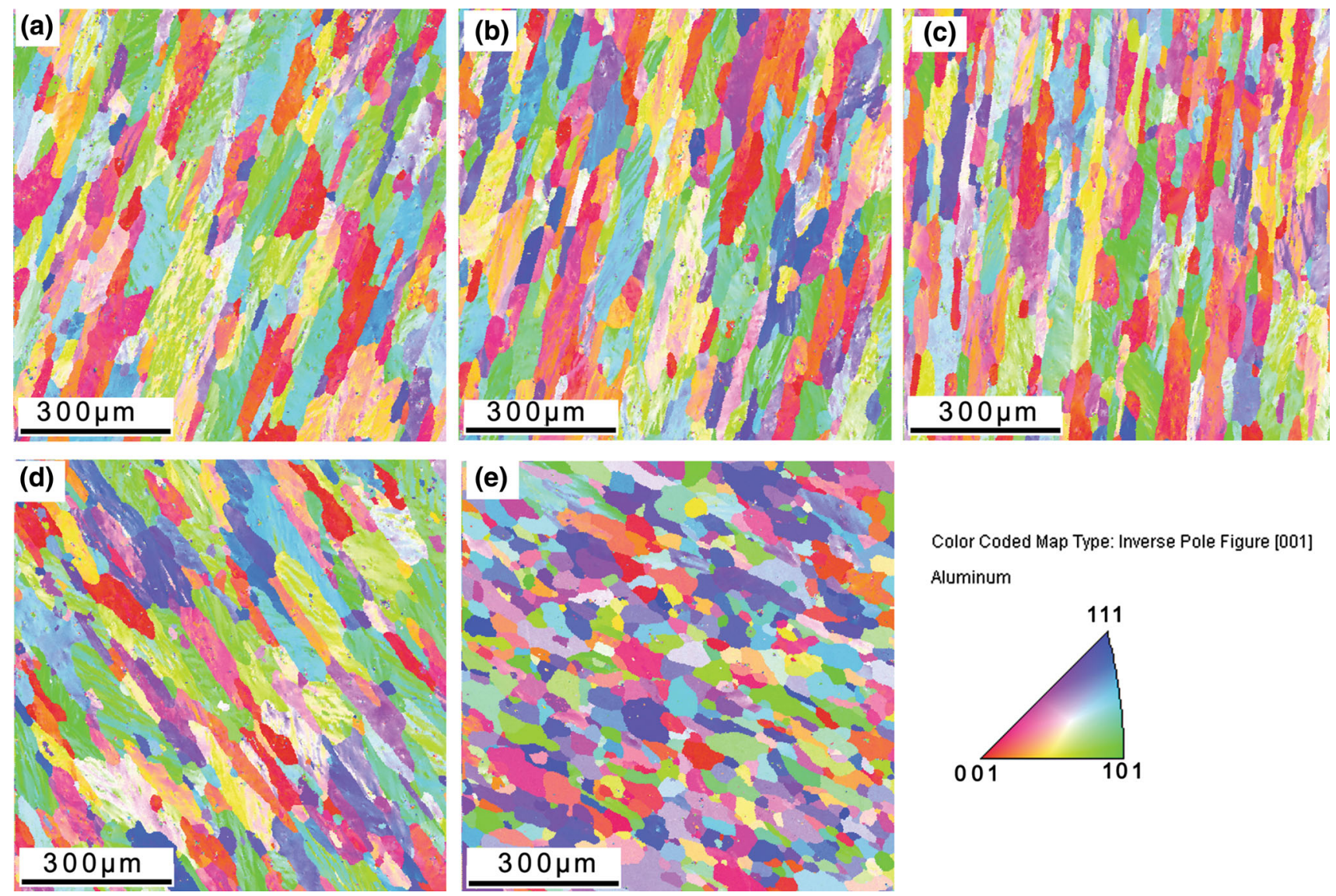

Color Coded Map Type: Inverse Pole Figure [001]

Aluminum

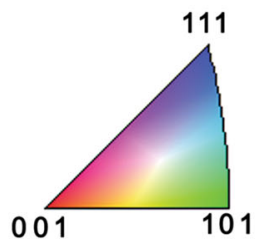

Fig. 3 Orientation maps of the HAZ samples with different $T_{\mathrm{p}}$ : a $200{ }^{\circ} \mathrm{C}, \mathbf{b} 300{ }^{\circ} \mathrm{C}, \mathbf{c} 400{ }^{\circ} \mathrm{C}, \mathbf{d} 500{ }^{\circ} \mathrm{C}$, e $550{ }^{\circ} \mathrm{C}$ 


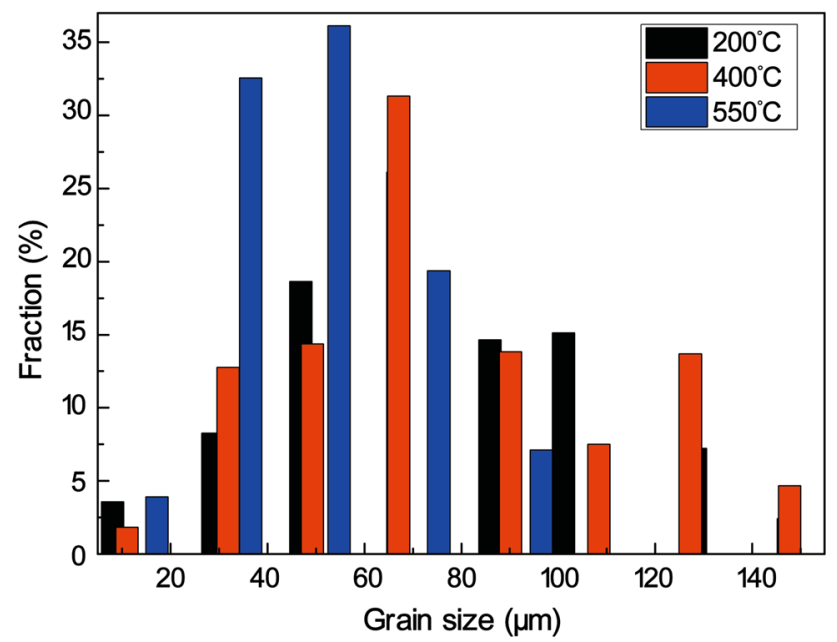

Fig. 5 Distribution of the grain diameter at $T_{\mathrm{p}}$ of 200, 400 and $550{ }^{\circ} \mathrm{C}$

The Taylor factor $(M)$ was next examined. For the facecentered cubic ( $\mathrm{fcc}$ ) polycrystal of the 2219 aluminum alloy, the $\{111\}<110>$ slip systems were dominant and were considered for the $M$ calculations [19]. The larger values of $M$ denote orientations that are more resistant to plastic deformation under a specified strain path [9]. The value of $M$ was determined for each sample as shown in Table 2. The variation of the value of $M$ is very small for the samples with the $T_{\mathrm{p}}$ in the range of $200-400{ }^{\circ} \mathrm{C}$. With a further increase of the $T_{\mathrm{p}}$, the value of $M$ also increases and reaches the maximum at the $T_{\mathrm{p}}$ of $550{ }^{\circ} \mathrm{C}$.

\subsection{Behavior of Precipitates}

Figure 6 shows the typical TEM images of simulated specimens with different $T_{\mathrm{p}}$. In Fig. 6a, disk-shaped precipitates 20-120 nm long can be observed. Based on the selected area electron diffraction (SAED) patterns from this region and the locations of typical precipitates diffraction reflections and double diffraction effects for this alloy, the disk-shaped precipitates are considered to be the typical metastable GP zone $/ \theta^{\prime}$ phase [9]. These precipitates are partially or completely coherent with the matrix and are the main strengthening precipitates. The size and volume fraction of the precipitates were measured for 500 random precipitates at different $T_{\mathrm{p}}$. The volume fraction $\left(f_{\mathrm{v}}\right)$ of the precipitates in a thin foil projection was determined according to the equation [20]:

Table 2 Taylor factor $(M)$ at different $T_{\mathrm{p}}$

\begin{tabular}{llllll}
\hline$T_{\mathrm{p}}$ & $200{ }^{\circ} \mathrm{C}$ & $300{ }^{\circ} \mathrm{C}$ & $400{ }^{\circ} \mathrm{C}$ & $500{ }^{\circ} \mathrm{C}$ & $550{ }^{\circ} \mathrm{C}$ \\
\hline Taylor factor $(M)$ & 2.84 & 2.84 & 2.84 & 2.93 & 3.12 \\
\hline
\end{tabular}

$f_{\mathrm{v}}=\frac{-2 \pi r}{\pi r+4 t} \ln (1-A)$

where $r$ is the radius of the precipitates, $t$ is the foil thickness and $A$ is the project area fraction of the precipitates, as determined by the point count method. The results are listed in Table 3. When the $T_{\mathrm{p}}$ reaches to $300{ }^{\circ} \mathrm{C}$ (Fig. 6b), the thermal cycle leads to a growth of the precipitates accompanied by a slight decrease in number density. The SAED pattern from this sample exhibits strong reflections from the $\theta^{\prime}$ precipitates but no reflections from the GP zone, which are not visible in the TEM image, indicating that the GP zone has transformed into the $\theta^{\prime}$ phase. The $\theta^{\prime}$ precipitates significantly coarsen at the $T_{\mathrm{p}}$ of $400{ }^{\circ} \mathrm{C}$ (Fig. 6c). The thickness of the $\theta^{\prime}$ precipitates is almost double that observed in the sample with the $T_{\mathrm{p}}$ of $300{ }^{\circ} \mathrm{C}$ and the length also increases by around $54 \%$. The larger precipitates with an irregular shape are identified as the $\theta$ phase by the corresponding SAED pattern. The orientation relationship between the $\theta$ phase and the $\alpha$ matrix can be written as $[0 \overline{1} 1]_{\theta} / /[\overline{1} 23]_{\alpha}$. As the $T_{\mathrm{p}}$ further increases to $500{ }^{\circ} \mathrm{C}$ (Fig. $6 \mathrm{~d}$ ), the $\theta^{\prime}$ precipitates almost disappear and the size and the number density of the $\theta$ precipitates increase. When the $T_{\mathrm{p}}$ increases to $550{ }^{\circ} \mathrm{C}$ (Fig. 6e), fine $\theta^{\prime}$ phases are absent and only some coarse precipitates are distributed throughout the matrix. Similar results, i.e., hardly any precipitates existed in HAZ adjacent to fusion zone were observed by Niu et al. [21]. The behavior of the precipitates can change the lattice parameters of the matrix and the concentration of $\mathrm{Cu}$ in the $\alpha$ phase. The XRD pattern of the simulated HAZ, shown in Fig. 7, was used to measure the lattice parameters of the matrix. In the 2219 alloy, the relationship between the concentration of $\mathrm{Cu}$ in the $\alpha$ phase $\left(C_{\mathrm{s}}, \mathrm{wt} \%\right)$ and the lattice parameter $(a, \mathrm{~nm})$ of the $\alpha$ phase $[11,22]$ can be expressed as:

$a=a_{0}-p C_{\mathrm{s}}$,

where $p$ is a constant $\left[p=2.06 \times 10^{-4} \mathrm{~nm} /(\mathrm{wt} \%)\right]$ [22], and $a_{0}=0.40496 \mathrm{~nm}$ is the lattice parameter of pure aluminum. The corresponding $\mathrm{Cu}$ concentration in the $\alpha$ phase is listed in Table 3. The lattice parameter of the $\alpha$ phase first increases as the $T_{\mathrm{p}}$ increases to $400{ }^{\circ} \mathrm{C}$, then decreases at the $T_{\mathrm{p}}$ of $500{ }^{\circ} \mathrm{C}$ and above. Therefore, the welding thermal cycles caused the transformation of a fraction of the GP zone and $\theta^{\prime}$ phases to equilibrium $\theta$ phases, while the remaining fraction dissolved into the matrix.

\subsection{Mechanical Properties}

The micro-hardness and micro-tensile test results are presented in Fig. 8. Unsurprisingly, BM exhibited the highest hardness value $(136.0 \pm 10.2 \mathrm{HV} 0.1)$. The hardness 

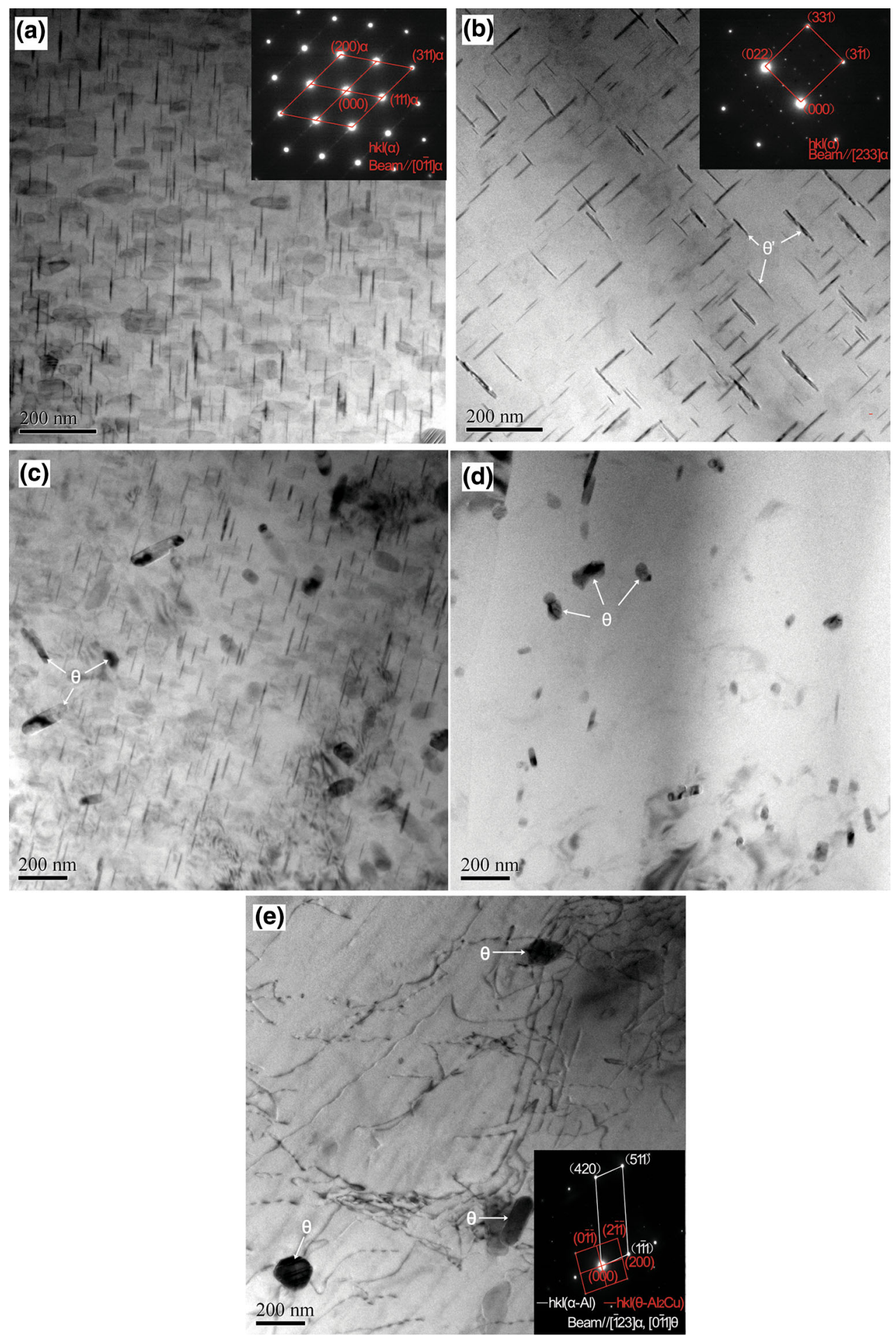

Fig. 6 TEM micrographs of the simulated HAZ at different $T_{\mathrm{p}}$ and the selected area electron diffraction patterns from this region: a $200{ }^{\circ} \mathrm{C}$, b $300{ }^{\circ} \mathrm{C}$, c $400{ }^{\circ} \mathrm{C}$, d $500{ }^{\circ} \mathrm{C}$, e $550{ }^{\circ} \mathrm{C}$

continuously decreases as the $T_{\mathrm{p}}$ is increased to $500{ }^{\circ} \mathrm{C}$, while the hardness exhibits the lowest values $(79.8 \pm 4.0 \mathrm{HV} 0.1)$ at the $T_{\mathrm{p}}$ of $500{ }^{\circ} \mathrm{C}$. Compared with the $\mathrm{BM}$, the hardness values of the specimens with the $T_{\mathrm{p}}$ of $200,300,400$ and $500{ }^{\circ} \mathrm{C}$ are reduced by about $8,14,26$ and $42 \%$, respectively. When the $T_{\mathrm{p}}$ is $550{ }^{\circ} \mathrm{C}$, the hardness value (93.8 $\pm 7.1 \mathrm{HV0.1})$ is slightly higher than that of the specimen with $T_{\mathrm{p}}$ of $500{ }^{\circ} \mathrm{C}$, but still lower than that of other specimens. The measured tensile strength of the BM specimen is about $475 \pm 6 \mathrm{MPa}$, which is higher than the 
Table 3 Quantitative analysis results of the microstructures of the simulated HAZ at different $T_{\mathrm{p}}$

\begin{tabular}{|c|c|c|c|c|c|}
\hline$T_{\mathrm{p}}$ & $200{ }^{\circ} \mathrm{C}$ & $300{ }^{\circ} \mathrm{C}$ & $400{ }^{\circ} \mathrm{C}$ & $500{ }^{\circ} \mathrm{C}$ & $550{ }^{\circ} \mathrm{C}$ \\
\hline Length of the $\theta^{\prime}$ phase $(\mathrm{nm})$ & 55.6 & 62.5 & 85.5 & - & - \\
\hline Thickness of the $\theta^{\prime}$ phase (nm) & 7.0 & 7.3 & 13.2 & - & - \\
\hline$f_{\mathrm{v}}$ of the $\theta^{\prime}$ phase $(\%)$ & 17.7 & 16.5 & 11.6 & - & - \\
\hline$f_{\mathrm{v}}$ of the $\theta^{\prime}$ (form from $\theta^{\prime}$ ) $(\%)$ & - & - & 4.4 & 9.6 & 9.5 \\
\hline Lattice parameter of $\alpha(\mathrm{nm})$ & 0.40409 & 0.40425 & 0.40439 & 0.40421 & 0.40413 \\
\hline $\mathrm{Cu}$ concentration in $\alpha(\mathrm{wt} \%)$ & 4.22 & 3.45 & 2.77 & 3.64 & 4.03 \\
\hline
\end{tabular}
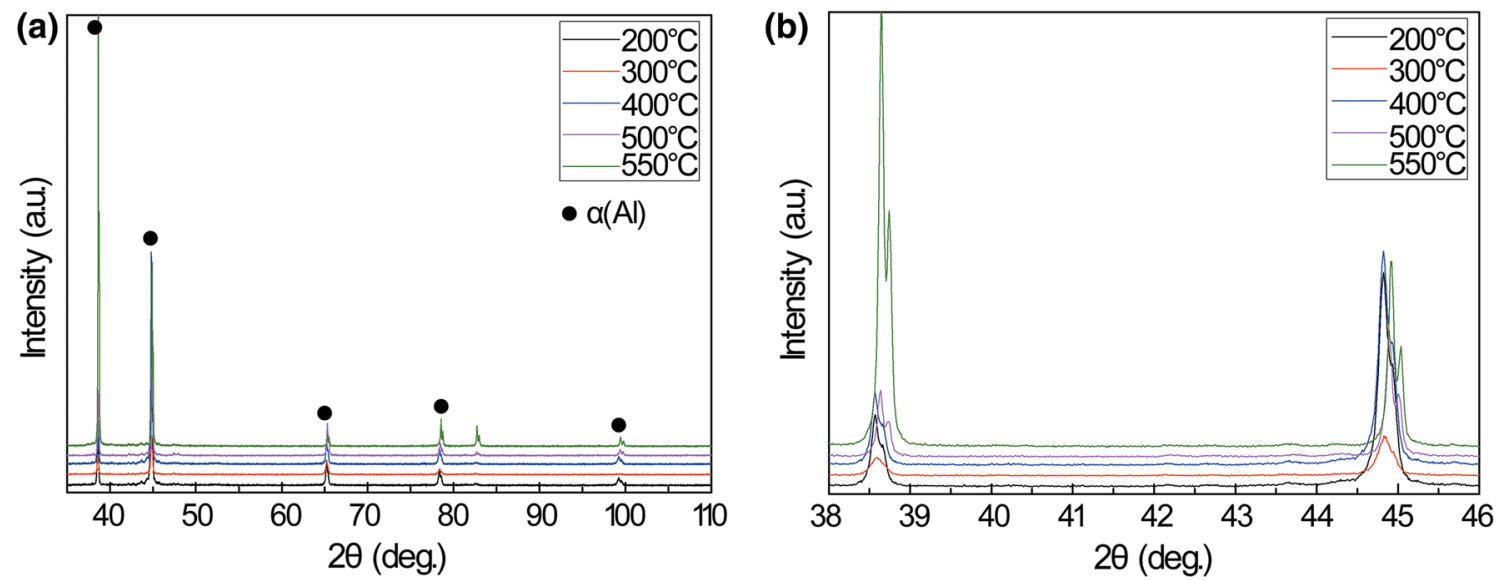

Fig. 7 XRD patterns of the simulated HAZ: a XRD pattern for $2 \theta$ from $35^{\circ}$ to $110^{\circ}$, $\mathbf{b}$ the magnified image of the first two peaks

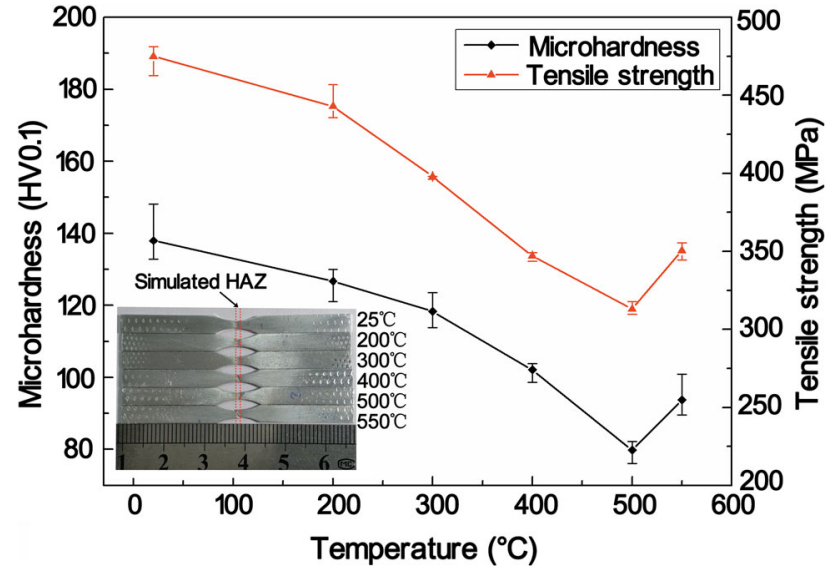

Fig. 8 Micro-hardness profile and tensile strength profile for the base metal $\left(20^{\circ} \mathrm{C}\right)$ and the thermally cycled specimens at different $T_{\mathrm{p}}$

tensile strength of the HAZ specimens. The samples with $T_{\mathrm{p}}$ of $500{ }^{\circ} \mathrm{C}$ exhibit the lowest tensile strength of $313 \pm 4 \mathrm{MPa}$, indicating a $34 \%$ reduction in strength values.

The mechanical properties of the HAZ are related to the grain size, the amount and size of precipitates and the $\mathrm{Cu}$ concentration in $\alpha$ matrix. The metastable, disk-shaped $\theta^{\prime \prime}$ and $\theta^{\prime}$ phases are the main strengthening precipitates for the AA2219 aluminum alloy [23, 24]. The uniform distribution of the fine precipitates in the matrix can impede the dislocation motion. Optimally, the precipitates can be bypassed by dislocations instead of being cut by dislocations. The increase in the yield strength via the Orowan strength $\left(\Delta \sigma_{\text {or }}\right)$ mechanism can be analyzed as follows [25]:

$\Delta \sigma_{\mathrm{or}}=\frac{K M G b}{\lambda(1-v)^{1 / 2}} \ln \left(d_{\mathrm{s}} / b\right)$,

$\lambda=\left[\frac{1}{2}\left(\frac{2 \pi}{3 f_{\mathrm{v}}}\right)^{\frac{1}{2}}-1\right]\left(\pi d_{\mathrm{m}} / 4\right)$,

where $K$ is a constant depending on the particle size and distribution, $M$ is the Taylor factor, $G=0.27 \times 10^{5} \mathrm{MPa}$ is the shear modulus, while $v=0.345$ and $b=0.286 \mathrm{~nm}$ are the $\alpha$-Al matrix Poisson's ratio and the magnitude of the Al Burgers vector, respectively [26]. Moreover, $d_{\mathrm{s}}=\pi d_{\mathrm{m}} / 4$ and $\lambda$ are the mean particle diameter and an effective inter-particle distance on the dislocation slip planes, respectively, and finally, $d_{\mathrm{m}}$ is the measured mean particle size. Equation (5) indicates that a larger volume fraction and a smaller size of the particles can increase the yield strength. In this study, the thermal cycles caused the dissolution and coarsening of the $\theta^{\prime}$ precipitates in the simulated HAZ as the $T_{\mathrm{p}}$ was increased. Although the 
(a)

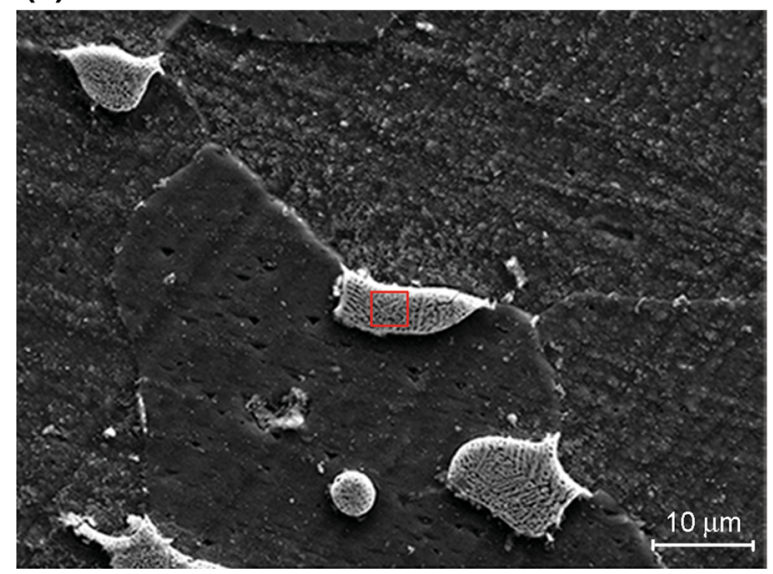

(b)

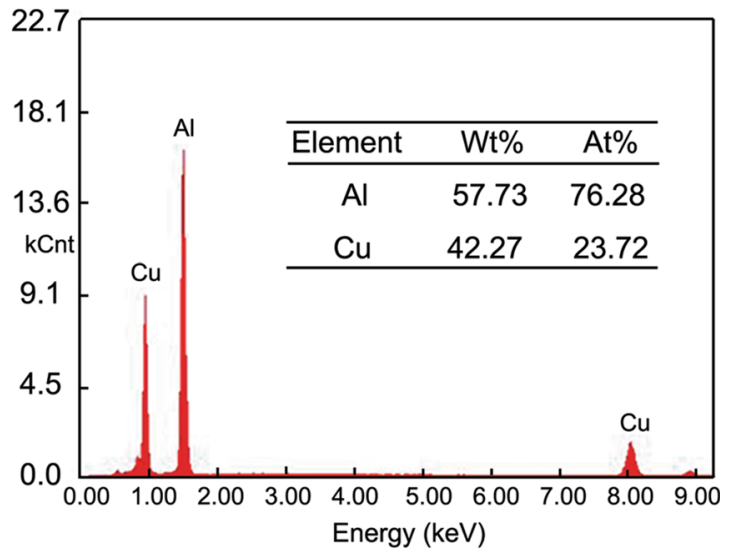

Fig. 9 SEM micrograph and the EDS analysis of the lamellar particle at $T_{\mathrm{p}}$ of $550{ }^{\circ} \mathrm{C}$

number of the $\theta$ precipitates increased, the overall volume fraction of the precipitates decreased (Table 3). Therefore, the Orowan strength effect became weaker, resulting in the reduced strength in the simulated HAZ.

However, it is noteworthy that the HAZ experiencing the $T_{\mathrm{p}}$ of $550{ }^{\circ} \mathrm{C}$ exhibited slightly higher micro-hardness and strength. This may be explained by the combined effects of the precipitation strengthening, solid solution strengthening and grain refining strengthening. The finer grain size leads to Hall-Petch strengthening, $\Delta \sigma_{\mathrm{HP}}$, expressed as [27]:

$\Delta \sigma_{\mathrm{HP}}=k d^{-1 / 2}$

where $d$ is the average grain size and $k$ is a materialdependent constant. For this aluminum alloy, the value of the constant ' $k$ ' was determined to be about $2.1 \mathrm{MPa} \mathrm{mm}^{1 /}$ ${ }^{2}$ (Ref. [28]), which is almost ten times smaller than the value of this constant for steels. Therefore, the grain refining strengthening due to finer grain structures is not significant. Based on the Orowan strength mechanism, the relationship between the strength and $M$ is positively proportional. The maximum value of $M$ occurred at the $T_{\mathrm{p}}$ of $550{ }^{\circ} \mathrm{C}$ (Table 2). Besides, the $T_{\mathrm{p}}$ of $550{ }^{\circ} \mathrm{C}$ will induce dissolution of some precipitates. Therefore, the concentration of $\mathrm{Cu}$ in the $\alpha$ phase would increase. The correlation between the flow stress $(\sigma, \mathrm{MPa})$ and the alloy concentration $(C$, at. $\%)$ is expressed in the following formula [11]:

$\sigma=\sigma_{\text {pure }}+H C^{n}$

where $\sigma_{\text {pure }}(\mathrm{MPa})$ is the flow stress of a pure metal, and $H\left[\mathrm{MPa}(\text { at. } \%)^{-n}\right]$ and $n$ are constants relating to work hardening. In Eq. (7), $n$ is in the range of $0.5-0.75$ for the yield stress of pure fcc substitutional solid solutions, and it increases to about 1.0 for the commercial aluminum alloys [11]. At the $T_{\mathrm{p}}$ of $550{ }^{\circ} \mathrm{C}$, the solid solution strengthening effect also increases. Additionally, as shown in Fig. 9, a partial liquefaction occurs clearly on the grain boundaries and some large precipitates form within the grains. Because $550{ }^{\circ} \mathrm{C}$ is slightly above the eutectic reaction temperature $\left(548^{\circ} \mathrm{C}\right)$ [16], the inverse eutectic reaction between the $\theta$ particles and the surrounding $\alpha$ matrix $(\alpha+\theta \rightarrow \mathrm{L})$ occurred [29]. Figure 9b shows the EDS result of the region in the red rectangle where the determined $\mathrm{Cu} / \mathrm{Al}$ weight ratio is $42.27 / 57.73$. This ratio is lower than the $53 / 47$ ratio of the $\theta$ phase but higher than the 33/67 ratio of the eutectic $[11,16]$. The lamellar structure may consist of normal eutectic $(\alpha+\theta)$ as well as $\theta$ phase, which weakens the mechanical properties of the alloy. Although both solid solution strengthening and grain refining strengthening contribute to improve the mechanical properties for $T_{\mathrm{p}}$ of $550{ }^{\circ} \mathrm{C}$, the precipitation strengthening plays a much more important role. Therefore, the strength and hardness is much lower than that of BM.

\section{Conclusions}

1. The observed distributions of grain size in the HAZs were similar for the different $T_{\mathrm{p}}$, except for a $T_{\mathrm{p}}$ of $550{ }^{\circ} \mathrm{C}$. When the $T_{\mathrm{p}}$ was $550{ }^{\circ} \mathrm{C}$, a significant recrystallization occurred in the HAZ which was characterized by fine equiaxed-grain structure. In this case, the distribution of grain boundaries misorientation angles corresponded to the MacKenzie distribution.

2. The Taylor factor value $(M)$ was stable for the $T_{\mathrm{p}}$ values of $200-400{ }^{\circ} \mathrm{C}$ and then increased as $T_{\mathrm{p}}$ was further increased. The increase of $M$ can contribute to improve the mechanical properties, especially for the HAZ at the $T_{\mathrm{p}}$ of $550{ }^{\circ} \mathrm{C}$.

3. Thermal cycling can cause transformation of the numerous fine disk-shaped $\theta^{\prime \prime} / \theta^{\prime}$ phases into the coarse 
equilibrium $\theta$ phase. Part of the $\theta^{\prime}$ phase dissolved into the matrix when the $T_{\mathrm{p}}$ was above $500{ }^{\circ} \mathrm{C}$.

4. The softening in the simulated HAZ was mainly a result of the reduction of the disk-shape precipitates.

\section{References}

[1] G.V. Narayana, V.M.J. Sharma, V. Diwakar, K. Sree Kumar, R.C. Prasad, Sci. Technol. Weld. Join. 9, 121 (2013)

[2] X. Lei, Y. Deng, Z. Yin, G. Xu, J. Mater. Eng. Perform. 6, 2149 (2014)

[3] Z.Y. Zhu, C.Y. Deng, Y. Wang, Z.W. Yang, J.K. Ding, D.P. Wang, Mater. Des. 65, 1075 (2015)

[4] J.Q. Li, H.J. Liu, Int. J. Adv. Manuf. Technol. 76, 1469 (2015)

[5] C. Zhang, M. Gao, G. Li, C. Chen, X. Zeng, Sci. Technol. Weld. Join. 18, 703 (2013)

[6] P.L. Li, Z.F. Xu, C. Yu, H. Lu, J.S. Yao, Acta Metall. Sin. (Engl. Lett.) 25, 225 (2012)

[7] W. Woo, H. Choo, Sci. Technol. Weld. Join. 3, 267 (2013)

[8] M. Dumont, A. Steuwer, A. Deschamps, M. Peel, P. Withers, Acta Mater. 54, 4793 (2006)

[9] R.W. Fonda, J.F. Bingert, Metall. Mater. Trans. A 35, 1487 (2004)

[10] L. Löchte, A. Gitt, G. Gottstein, I. Hurtado, Acta Mater. 48, 2969 (2000)

[11] Q. Li, A. Wu, Y. Li, G. Wang, D. Yan, J. Liu, Mater. Sci. Eng. A 623, 38 (2015)
[12] E. Bousquet, A. Poulon-Quintin, M. Puiggali, O. Devos, M. Touzet, Corros. Sci. 53, 3026 (2011)

[13] D.S. Malarvizhi, D.V. Balasubramanian, Weld. World 56, 105 (2012)

[14] C.H. Luo, W.P. Peng, J.Q. Zhang, L.J. Guo, F.B. Dong, Trans. Mater. Heat Treat. 36, 35 (2015)

[15] T. Ma, G.D. Ouden, Mater. Sci. Eng. A 266, 198 (1999)

[16] W.Y. Zhang, Welding Metallurgy (Machinery Industry Press, Beijing, 1999), pp. 164-166

[17] J.K. MacKenzie, Biometrika 45, 229 (1958)

[18] I. Kalemba, K. Muszka, S. Dymek, C. Hamilton, Diffus. Defect Data Pt. B 203, 258 (2013)

[19] W. Tayon, R. Crooks, M. Domack, J. Wagner, A.A. Elmustafa, Exp. Mech. 50, 135 (2010)

[20] D.L. Gilmore, R.M. Starker Jr., Metall. Mater. Trans. A 28, 1399 (1997)

[21] L.Q. Niu, X.Y. Li, L. Zhang, X.B. Liang, M. Li, Acta Metall. Sin. (Engl. Lett.) 30, 438 (2017)

[22] H.J. Axon, W. Hume-Rothery, Proc. R. Soc. A 193, 1 (1948)

[23] V.M.J. Sharma, K.S. Kumar, B.N. Rao, S.D. Pathak, Mater. Sci. Eng. A 528, 4040 (2011)

[24] K.S. Arora, S. Pandey, M. Schaper, R. Kumar, Int. J. Adv. Manuf. Technol. 50, 941 (2010)

[25] A. Kelly, Strengthening Methods in Crystals (Elsevier Publishing Company, Amsterdam, 1971), pp. 9-135

[26] K.E. Knipling, R.A. Karnesky, C.P. Lee, D.C. Dunand, D.N. Seidman, Acta Mater. 58, 5148 (2010)

[27] N.J. Petch, J. Iron Steel Inst. 174, 25 (1953)

[28] S.R.K. Rao, G.M. Reddy, K.S. Rao, M. Kamaraj, K.P. Rao, Mater. Charact. 55, 345 (2005)

[29] C. Huang, S. Kou, Weld. J. 79, 113 (2000) 